\title{
Article \\ A Study on the Possibility of Using Iron Scale in the Construction of Electromagnetic Field Shields
}

\author{
Adam Jakubas ${ }^{1, *}$, Ewa Lada-Tondyra ${ }^{1} \mathbb{D}$, Marcin Makówka $^{2} \mathbb{D}$ and Łukasz Suchecki ${ }^{3}$ \\ 1 Faculty of Electrical Engineering, Czestochowa University of Technology, 42-200 Czestochowa, Poland; \\ lada-tondyra@pcz.pl \\ 2 Faculty of Mechanical Engineering, Lodz University of Technology, 90-539 Lodz, Poland; \\ marcin.makowka@p.lodz.pl \\ 3 Faculty of Mechanical Engineering and Computer Science, Czestochowa University of Technology, \\ 42-200 Czestochowa, Poland; lukasz.suchecki@pcz.pl \\ * Correspondence: adam.jakubas@pcz.pl
}

Citation: Jakubas, A.; Łada-Tondyra, E.; Makówka, M.; Suchecki, Ł. A Study on the Possibility of Using Iron Scale in the Construction of

Electromagnetic Field Shields. Energies 2022, 15, 1332. https:// doi.org/10.3390/en15041332

Academic Editor: Andrea Mariscotti

Received: 21 December 2021

Accepted: 7 February 2022

Published: 12 February 2022

Publisher's Note: MDPI stays neutral with regard to jurisdictional claims in published maps and institutional affiliations.

Copyright: (c) 2022 by the authors. Licensee MDPI, Basel, Switzerland. This article is an open access article distributed under the terms and conditions of the Creative Commons Attribution (CC BY) license (https:// creativecommons.org/licenses/by/ $4.0 /)$.

\begin{abstract}
Electromagnetic radiation can have a negative effect on electronic circuits, for example, by disrupting their work and communication. Therefore, there is a need to reduce or eliminate electromagnetic interference using shields. This paper focuses on using waste materials in the form of iron scale, which is easy and inexpensive to obtain for shielding. Iron scale is the result of gaseous or aqueous corrosion, due to which a superficial layer of metal oxides formed on the surface of heated metal objects as a result of their contact with air or water during an industrial process is developed. In this study, morphology, chemical, and phase composition measurements were carried out. The results show that all the iron-based materials investigated are mainly composed of iron oxides and pure iron. The polymer-iron composites with different quantitative and qualitative compositions were prepared to verify the shielding effectiveness. The electrical resistance, impact strength, and magnetic properties were measured, and dynamic mechanical thermal analysis and tensile strength tests were performed. The tests confirmed the suitability of iron scale for the construction of electromagnetic field shielding material. Iron scale is cheap and easy to obtain from iron-based waste materials. The developed composites are easy to form and use recycled material.
\end{abstract}

Keywords: electromagnetic radiation; iron scale; EMI shielding; waste materials; composites

\section{Introduction}

Environmental care and thus improving quality of life means that an increasingly important role is being given to proper waste management. The use of secondary raw materials supports a low-carbon economy and thus contributes to sustainable development. In addition, waste processing reduces landfill space. The basic principle of recycling is to reuse the same materials with the least amount of raw material and energy needed to process them. Recycling, that is, converting used products into a useful form, is one of the greatest challenges not only for modern material engineering but for many scientific disciplines, including electrical engineering. One of the branches of the economy with a large and untapped potential for waste reuse is electrical engineering materials [1-3]. The concept of using recycled and waste materials for electrotechnical applications is characterized by an eco-innovative approach to developing new products and methods of their production from materials whose potential has so far been wasted.

Radiation is one of the three methods of energy transfer, apart from conduction and convection. It takes place by emitting electromagnetic waves or particles from a radiation source. It does not require an intermediate material (e.g., conductor) between the emission source and the receiver-the waves or particles propagate even in vacuum. In the modern world, two types of electromagnetic fields are dominant-electric and magnetic fields of a low frequency (up to $30 \mathrm{kHz}$ ) and fields of a high frequency (above $30 \mathrm{kHz}$ ), including 
radio waves (of wavelengths of 1-3000 $\mathrm{m}$ and frequencies of 0.3-300 MHz) and microwaves (of wavelengths of 1-1000 $\mathrm{mm}$ and frequencies of $0.3-300 \mathrm{GHz}$ ) [4].

Radiation, particularly high-frequency radiation (e.g., emitted by cellular telephone systems, wireless communications, and medical, household, and personal-use devices, as well as devices and control systems for industrial processes), may have a negative effect and fail to follow other electronic systems, for example, computers, microcontrollers, and measurement systems [5].

The essence of the problem of electromagnetic interference (EMI) increases with an increase in the number of sources and power signals. It is particularly visible in the area of the development of the industrial Internet of Things and 5G technology [6]. As part of the EU's digital single market strategy, the European Commission has established that by 2025, the EU will accelerate the digitization of the EU and increase its competitiveness by launching networks with much greater potential, with $5 \mathrm{G}$ being one of the building blocks of the "gigabit society". To this end, EU member states are required to authorize the use of the new 5G $700 \mathrm{MHz}, 3.5 \mathrm{GHz}$, and $26 \mathrm{GHz}$ frequency bands [7]. Therefore, EMI shielding of both sources and exposed devices is needed and often required by regulations [8]. Different materials can be used in its construction $[9,10]$.

The design and composition of many different kinds of electromagnetic (EM) radiation protection equipment depend on their intended use. One possibility is to reflect radiation. For EM radiation to be reflected, the target must have elements that can interact with the electromagnetic field (charge carriers, e.g., electrons or holes). These types of shields are usually built from good electrical conductors. However, it is not a necessary condition for the material to have high electrical conductivity throughout its entire volume [11]. Examples include metal sheets (Fe-Si, Al., Ag, Au) and metal-polymer composites containing aluminum flakes and steel fibers [12-15]. The second significant method is radiation absorption. In order for the absorption of electromagnetic radiation to be effective, the material must have magnetic and/or electric dipoles interacting with the radiation [5]. Dipoles can be formed by metal oxides and materials with a high dielectric constant and high magnetic permeability; examples include mu-metal (mu-metal typically has relative permeability values of 80,000-100,000 compared to several thousand for ordinary steel), supermalloy (permeability values of approximately 800,000), and nanocrystalline-amorphous alloys (Figure 1).

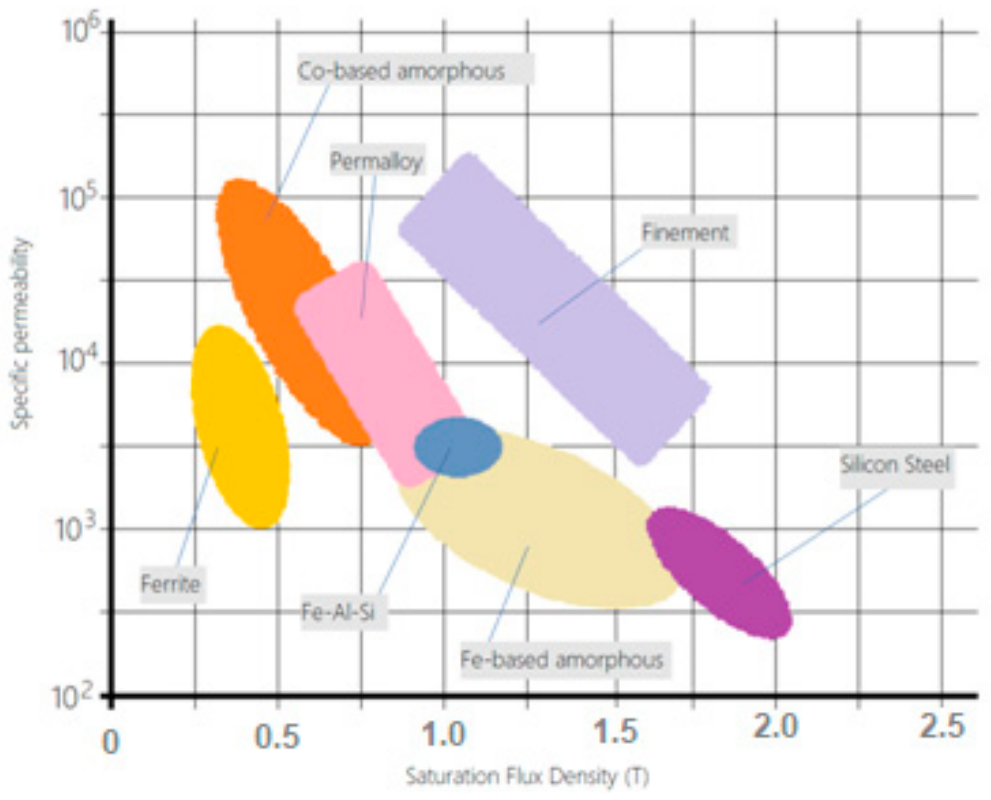

Figure 1. Relationship between magnetic permeability and magnetic induction in various types of soft magnetic materials. Own compilation based on [16]. 
In addition to reflection and absorption, the incident wave passing through a material can be reflected many times inside it (Figure 2). The shielding effectiveness (SE) of the material is defined in decibels $(\mathrm{dB})$, as follows [17]:

$$
\mathrm{SE}=20 \log _{10}\left(\frac{E_{\mathrm{out}}}{E_{\mathrm{in}}}\right),
$$

where $E_{\text {in }}\left(\right.$ or $\left.H_{\text {in }}\right)$ and $E_{\text {out }}\left(\right.$ or $\left.H_{\text {out }}\right)$ are the electric and magnetic field intensities of an electromagnetic wave induced in front of and behind the shield, respectively. Additionally, the shielding effectiveness can be divided into factors, as follows [18]:

$$
\mathrm{SE}(\mathrm{dB})=R(\mathrm{~dB})+A(\mathrm{~dB})+M(\mathrm{~dB}),
$$

where $R(\mathrm{~dB}), A(\mathrm{~dB})$, and $M(\mathrm{~dB})$ represent reflection loss, absorption attenuation, and additional multiple reflection effects, respectively.

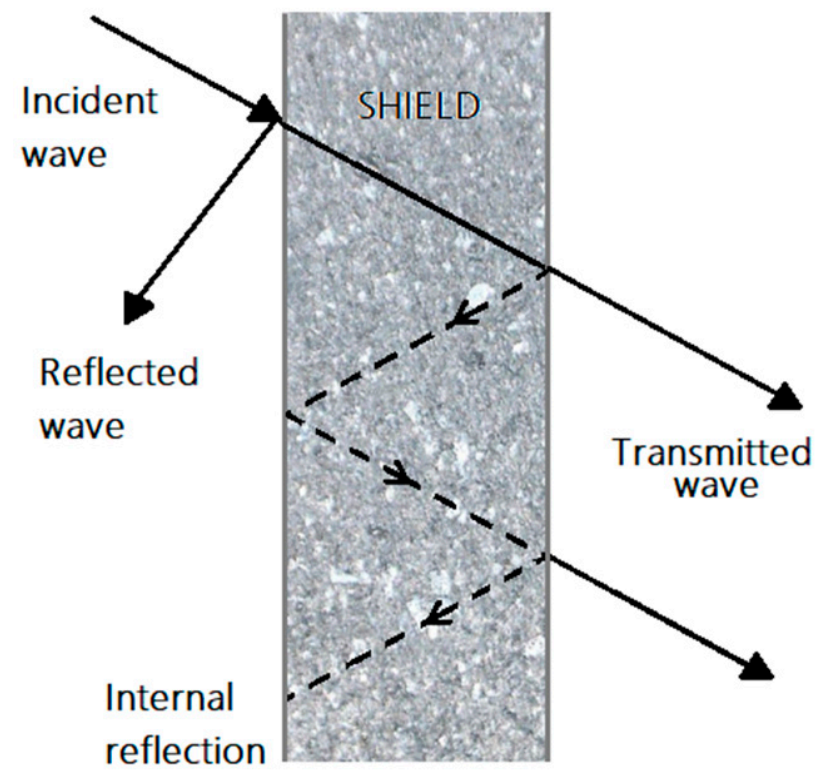

Figure 2. Diagram of transition of an incident electromagnetic wave through a material. Own compilation based on [17].

Various materials are used for shielding the field, and the scientific community is looking for more advanced and effective combinations, for example, nanomaterials (including carbon and ferrite nanotubes and powders), nanocrystalline and amorphous alloys, mu-metals, and many others [19]. The focus of this paper is on the use of iron scale waste materials $[20,21]$ for shielding, which are easy and cheap to obtain and form. In addition, the screen construction process should involve as few processing steps as possible. Such materials could be used as shielding enclosures for electronic devices as well as wall elements in buildings.

\section{Materials and Methods}

Iron scale is the result of gas or aqueous corrosion. It is a layer of metal oxides formed on the surface of iron-based metal objects as a result of their contact with air and water. It can form as a powder or flake scale (Figure 3) and consists of the iron oxides $\mathrm{Fe}_{2} \mathrm{O}_{3}$ (hematite), $\mathrm{Fe}_{3} \mathrm{O}_{4}$ (magnetite), and $\mathrm{FeO}$ (wustite) that tightly adhere to the substrate. The thickness of the scale is most frequently in the range of 5 to $65 \mu \mathrm{m}$, and its average value is $15 \mu \mathrm{m}$ [22]. In the production process, it is usually removed mechanically with the use of a high-pressure waterjet or by forging. 


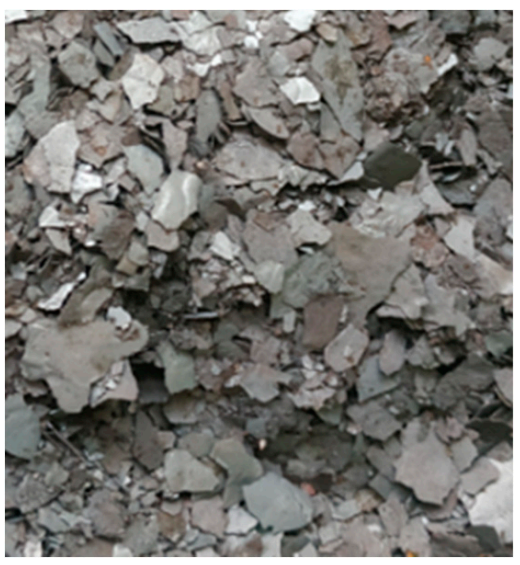

(a)

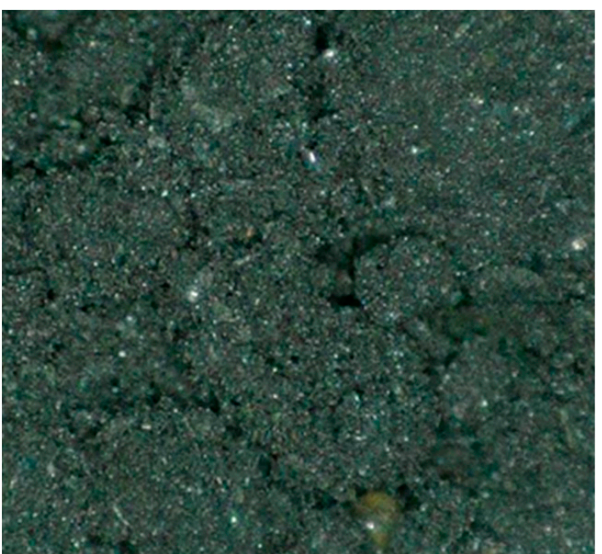

(b)

Figure 3. Iron oxide in the form of (a) flakes, (b) powder.

Tests were conducted on different types of samples with the following percentage compositions:

- unfilled polyethylene;

- from 10 to $90 \%$ polyethylene + from 90 to $10 \%$ iron scale.

The polyethylene used in the work was obtained from recycling. The plastic was cleaned, shredded, and prepared for processing. High-density polyethylene (HDPE), along with other varieties of polyethylene and polypropylene, belongs to the group of polyolefin plastics. It is estimated that the demand for polyolefins makes up over $40 \%$ of the demand for all polymers in Europe. High-density polyethylene is a partially crystalline polymer, characterized by high resistance to chemical agents, low weight, good abrasion resistance, good dielectric properties, and low water absorption. Due to its properties, it is used as a raw material for the production of all kinds of packaging, films, pipes, toys, and machine elements. The combination of HDPE with various other materials gives such a composite new properties. For example, the addition of fumed silica to HDPE increased the permeability of the new nanocomposites, while the addition of clay decreased the permeability [23].

\subsection{Morphology, Chemical, and Phase Composition Measurements}

Observations of the sizes and shapes of the powders were carried out by means of scanning microscopy with the use of a JEOL JSM-6610LV scanning electron microscope (JEOL Ltd., Japan). The chemical compositions were investigated with the help of the energy-dispersive X-ray spectroscopy technique (EDS) with the X-MAX 80 EDS module (Oxford Instruments Nano Analysis and Asylum Research, UK). The morphologies and chemical compositions were investigated with the following parameters: an accelerating voltage of $20 \mathrm{kV}$ at a high vacuum mode, and a beam current (spot size) value set for the best sharpness of the image or the strongest signal for EDS measurements.

Measurements of the phase compositions of the powders were carried out by means of X-Ray diffraction in the theta/theta system using a PAN analytical Empyrean X-ray diffractometer (Malvern Panalytical, UK) with a cobalt anode. The measurements were carried out with the following parameters: an S-Ray wavelength of $\lambda \mathrm{CoK}_{\alpha 1}=1.78901 \AA$, generator settings of $45 \mathrm{~mA}, 40 \mathrm{kV}$, start and end positions of $2 \theta 20 \mathrm{deg}-150 \mathrm{deg}$, an angle step value of $0.05 \mathrm{deg}$, and a scan step time $60 \mathrm{~s}$.

Sample images of powders used for the production of composites made with the use of the SEM microscope are shown in Figure 4. Estimated chemical compositions of powder materials determined by EDS and results of phase composition investigation are given in Table 1. 


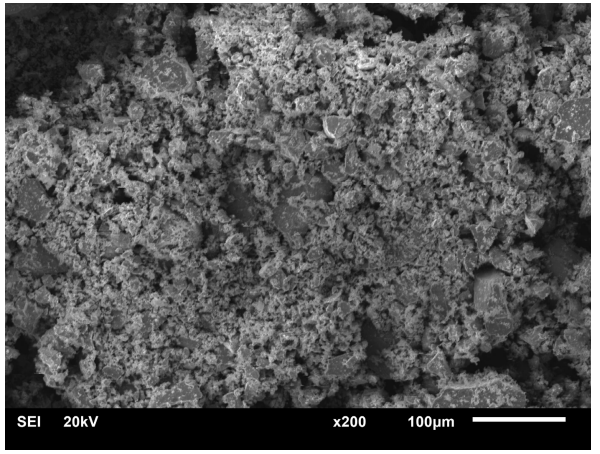

(a)

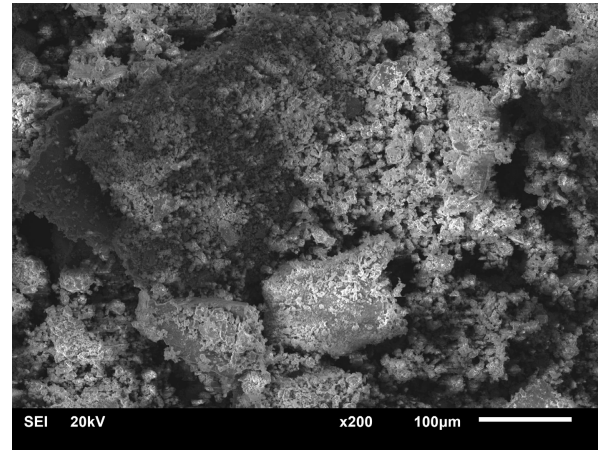

(b)

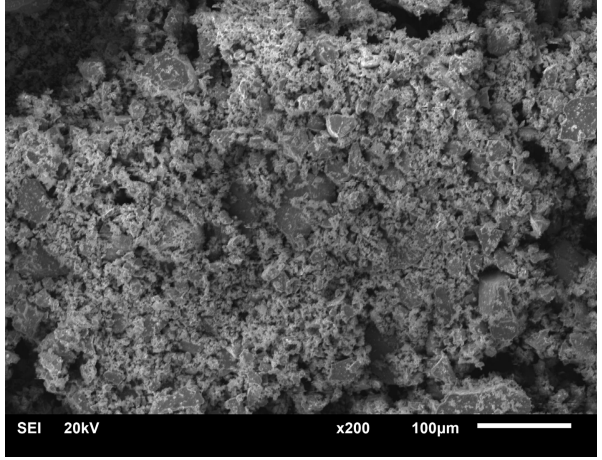

(c)

Figure 4. SEM images of powders: (a) flake scale, (b) powder scale, (c) iron oxides.

Table 1. Estimated chemical compositions of used materials.

\begin{tabular}{cccc}
\hline \multirow{2}{*}{ Element } & Flake Scale & Powder Scale & Iron Oxides \\
\cline { 2 - 4 } & & Chemical Composition (wt.\%) & \\
\hline $\mathrm{O}$ & 35 & 25 & 26 \\
\hline $\mathrm{Si}$ & - & 3 & - \\
\hline $\mathrm{C}, \mathrm{Al}$ & $<1$ & $<1$ & Balance \\
\hline $\mathrm{Fe}$ & Balance & Balance & + \\
\hline $\mathrm{Phase}$ & & Phase composition & + \\
\hline $\mathrm{Fe}_{3} \mathrm{O}_{4}$ & + & + & + \\
\hline $\mathrm{Fe}_{2} \mathrm{O}_{3}$ & + & + & + \\
\hline $\mathrm{Fe}_{0.925} \mathrm{O}$ & - & - & \\
\hline
\end{tabular}

The thicknesses of the scale flakes were in the order of 20-30 $\mu \mathrm{m}$, and their sizes ranged from several hundred microns to several millimeters. There was also visible fine powder of micrometer size. The shapes and particle sizes of the other two samples differed significantly from the flake scale. In the tested sample of the powder scale, it was noticed that it consisted of irregularly shaped particles of different forms and sizes from $2 \mu \mathrm{m}$ to approximately $100 \mu \mathrm{m}$. A part of them coagulated to particles of sizes up to $500 \mu \mathrm{m}$. Similar particle sizes were found in the iron oxide sample; however, there was a much greater fraction of particles of sizes of $2-5 \mu \mathrm{m}$.

Due to the limitations of the EDS method and the possibility that a considerable error in the estimation of the elemental composition might occur-especially in the case of estimating the content of light and heavy elements simultaneously $(\mathrm{O}, \mathrm{C}$, and $\mathrm{Fe})$ - the values were given up to the $\pm 1 \mathrm{wt}$. $\%$ accuracy. These results should be treated mainly as supplementary qualitative information to the results of the phase compositions of the investigated samples.

The results of the EDS analysis show that all of the tested materials were composed mainly of iron and oxygen atoms with a residual addition of $\mathrm{Al}(<1 \mathrm{wt} . \%)$. Si content was found only in the sample of the dust scale. All tested materials contained carbon atoms; however, due to the limitations of the EDS method, the carbon content was estimated to be lower than $1 \mathrm{wt} . \%$.

Phases of $\mathrm{Fe}_{2} \mathrm{O}_{3}$ (with the diffraction peaks best matching the pattern of the ICDD card no. 01-076-4579) and $\mathrm{Fe}_{3} \mathrm{O}_{4}$ (corresponding to the ICDD card no. 04-006-1668) were found in the sample of the flake scale. A similar composition was found in the case of the dust scale; however, it best matched different ICDD card numbers-01-080-7077 for the $\mathrm{Fe}_{2} \mathrm{O}_{3}$ phase and 04-002-2709 for the $\mathrm{Fe}_{3} \mathrm{O}_{4}$ phase. In the case of the third sample of iron oxides, the identified phases included $\mathrm{Fe}_{2} \mathrm{O}_{3}$ (01-076-4579) and $\mathrm{Fe}_{3} \mathrm{O}_{4}$ (04-011-5952), 
with the addition of $\mathrm{Fe}_{0.925} \mathrm{O}$ phase (04-008-0276). In all three of the cases, no iron phase $\left(\mathrm{Fe}_{\alpha}\right.$ or $\left.\mathrm{Fe}_{\gamma}\right)$ was detected. The results of the comparison of the chemical compositions of the samples with their phase compositions show that the atomic ratio of Fe/O from EDS indicates an oxygen deficiency, possibly due to the limitations of the SEM-EDS technique.

\subsection{Sample Preparation}

In order to carry out the investigations, mixtures of iron scales with HDPE powder of different quantitative and qualitative compositions were prepared. The content of the flake scale ranged from 20 to $80 \mathrm{wt}$. $\%$, and that of the powder scale ranged from 20 to $60 \mathrm{wt} . \%$. With greater shares of the iron scale in the mixture, the samples became too brittle and were not suitable for investigations. A deviation from the compositions mentioned above took place in the case of toroidal samples, for which, due to their greater thickness $(\sim 10 \mathrm{~mm})$, it was possible to obtain a stable mixture at $99 \mathrm{wt} . \%$ of the scale and with $1 \mathrm{wt} . \%$ of HDPE. On the basis of these compositions, three types of samples were prepared in the shapes of square plates (Figure 5), toroids (Figure 6), and paddle-shaped samples (Figure 7). The plate-shaped samples were used to measure the electrical resistance, impact strength, and EMI attenuation. The toroidal samples were used to measure the magnetic properties. In contrast, the paddle-shaped samples were used in the dynamic mechanical thermal analysis (DMTA) and tensile strength tests.

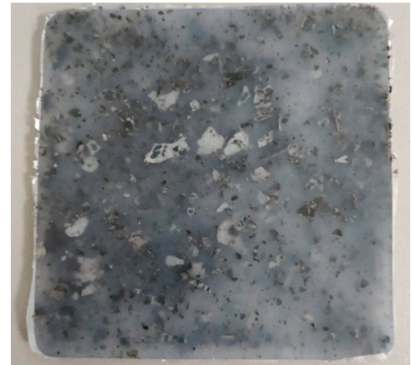

(a)

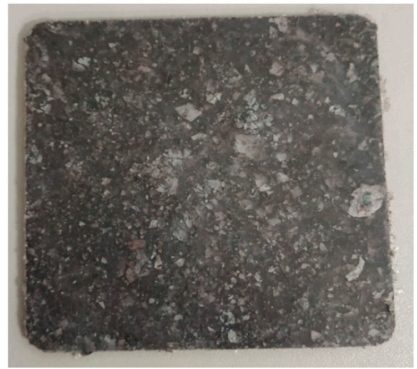

(b)

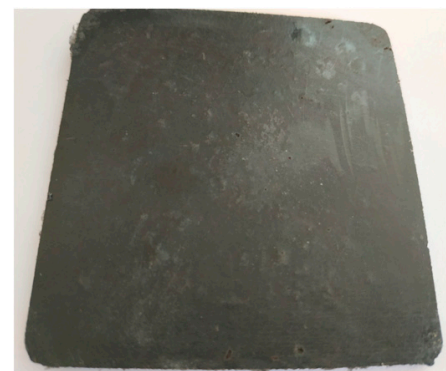

(c)

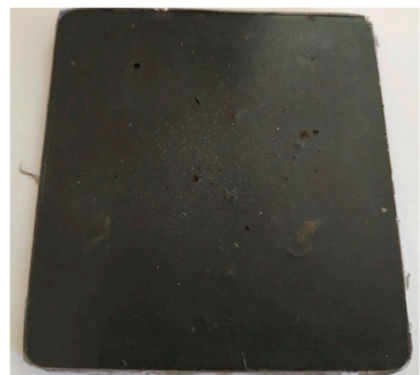

(d)

Figure 5. Examples of samples with the content of milled scale flakes at (a) $20 \%$, (b) $80 \%$, and mill scale powder at (c) $20 \%$, (d) $60 \%$.

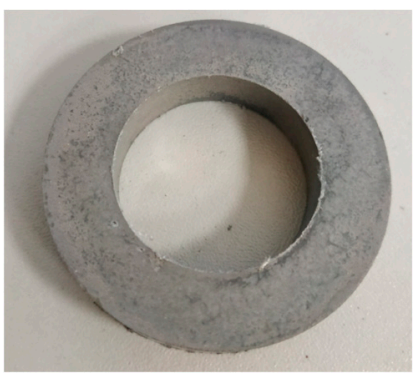

(a)

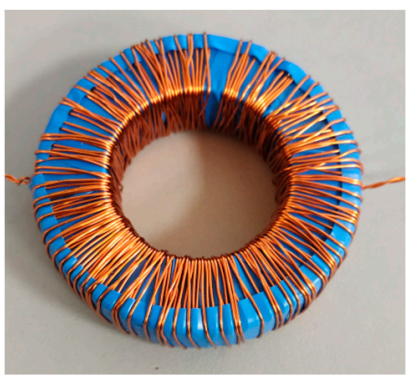

(b)

Figure 6. Examples of toroidal samples; (a) core, (b) core with winding.

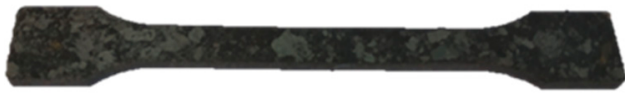

Figure 7. Example of "paddle" sample.

Recycled powdered high-density polyethylene was used as the composite matrix. The process of producing the shields consisted of homogenization of the mixtures in a drum mixer. They were then compacted in a mold under a pressure of $15 \mathrm{MPa}$ and formed under a pressure of $8 \mathrm{MPa}$ and at a temperature of $165^{\circ} \mathrm{C}$ (Figure 8). For the toroidal samples, the 
forming pressure was $500 \mathrm{MPa}$. The obtained samples, depending on the purpose, were $2 \mathrm{~mm}$ to $10 \mathrm{~mm}$ thick.

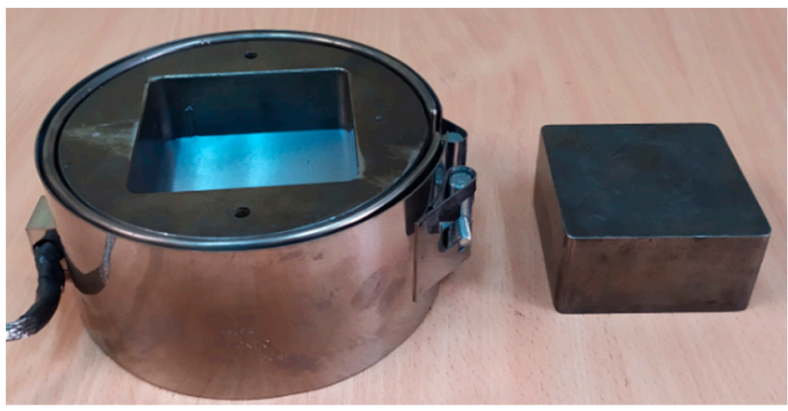

(a)

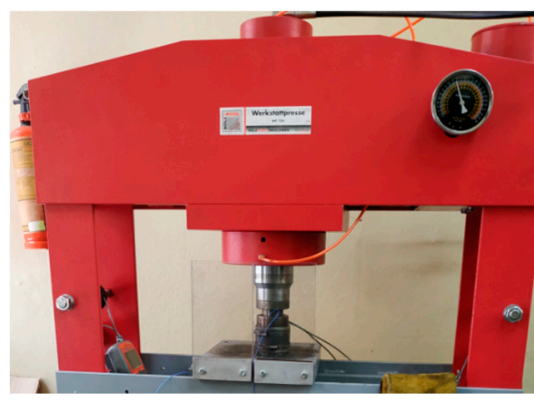

(b)

Figure 8. Stand for the production of samples, (a) an example of a mold and (b) a press used to prepare samples.

\section{Results and Discussion}

3.1. Measurement of Electrical and Magnetic Properties

Throughout the process, a number of tests were carried out to determine the variant of the iron scale-HDPE composition with optimal shielding and mechanical properties. Figure 9 shows the electrical volume resistance values for samples of the thickness of $2 \mathrm{~mm}$.

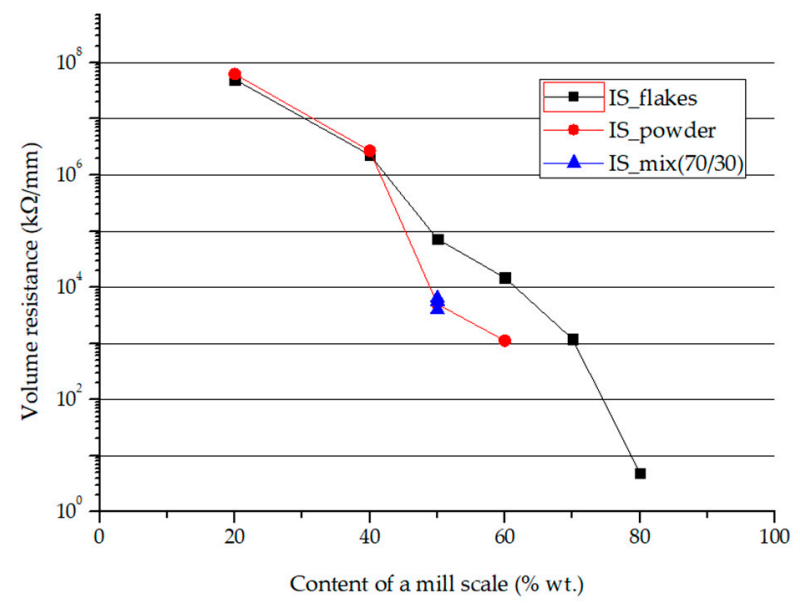

Figure 9. Volume resistance values.

The magnetic properties were determined using a computer-controlled measuring stand, the operational diagram of which is shown in Figure 10.

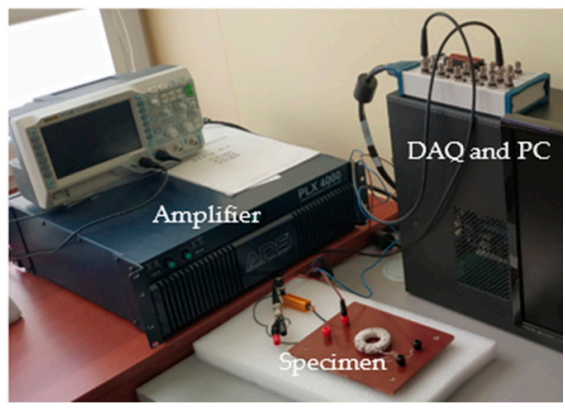

(a)

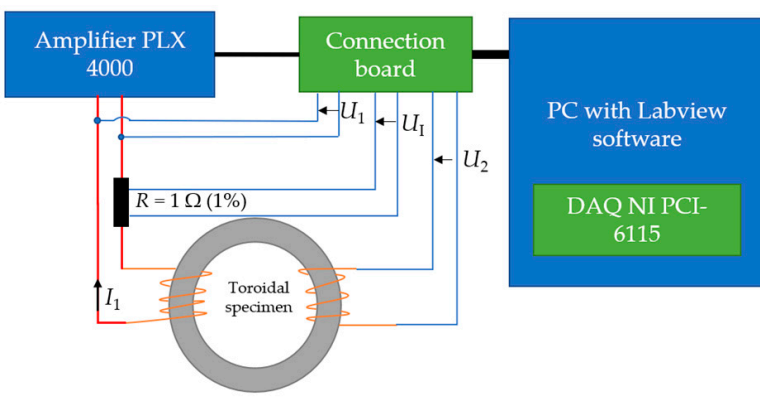

(b)

Figure 10. Test stand for measuring magnetic properties, (a) view of the magnetic properties measuring system, (b) scheme of the test stand. 
The most important element of the measuring system was the DAQ NI PCI-6110 card used with LabView software (Austin, TX, USA). The generated sinusoidal signal (also using the DAQ card) was amplified using the PLX 4000 power amplifier to obtain a current excitation on the resistor R1 ( $1 \Omega$, power of $100 \mathrm{~W}$, tolerance of $1 \%)$. During the preliminary tests, it was found that the magnetization frequency had a negligible effect on the shape of the hysteresis loop when $\mathrm{f} \leq 50 \mathrm{~Hz}$. Accordingly, the characteristics presented at $50 \mathrm{~Hz}$ can be considered quasi-static. Figure 11 shows the waveforms of the magnetization curves for the mill scale with different fractions.

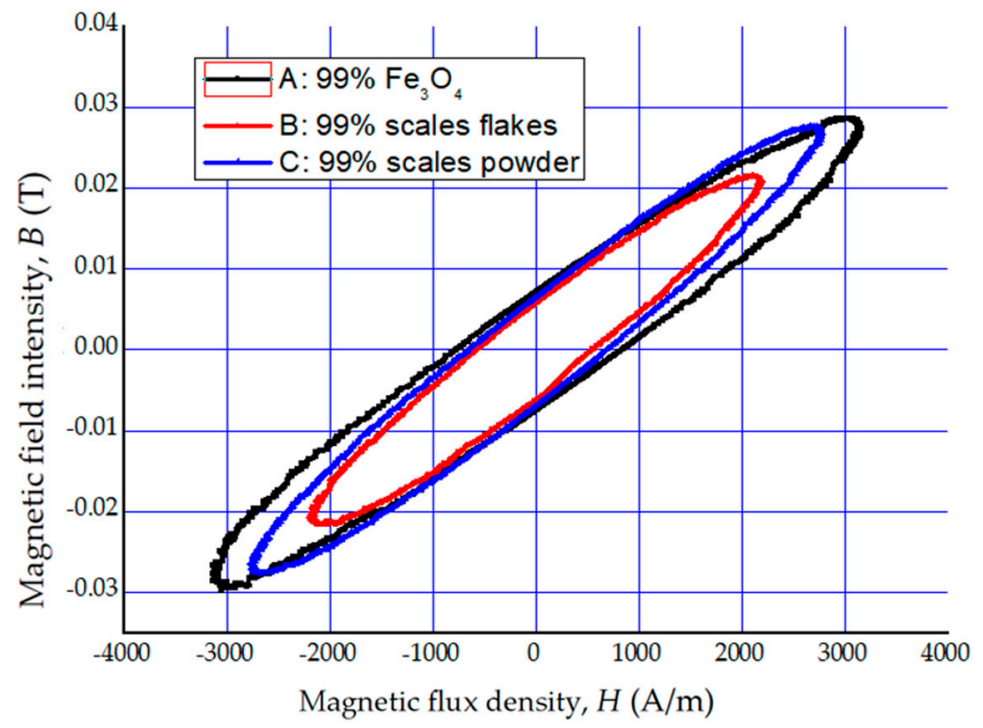

Figure 11. Hysteresis loop for composite (A): $99 \%$ pure $\mathrm{Fe}_{3} \mathrm{O}_{4}$ and $1 \%$ HDPE matrix, $B_{\max }=0.029$ $\mathrm{T}, H_{\max }=3150 \mathrm{~A} / \mathrm{m}, \mu_{\mathrm{r}}=7.4$, @ $50 \mathrm{~Hz}$. (B): 99\% scales flakes and $1 \%$ HDPE matrix, $B_{\max }=0.028 \mathrm{~T}$, $H_{\max }=2778 \mathrm{~A} / \mathrm{m}, \mu_{\mathrm{r}}=7.9$, @ $50 \mathrm{~Hz}$. (C): 99\% scales powder and $1 \%$ HDPE matrix, $B_{\max }=0.021 \mathrm{~T}$, $H_{\max }=2195 \mathrm{~A} / \mathrm{m}, \mu_{\mathrm{r}}=7.8$, @ $50 \mathrm{~Hz}$.

The values of the measured magnetic parameters are similar to those obtained by Azis et al. [24] despite the fact that in the present study, the authors examined the iron scale with a different composition (different source of origin) and incorrectly assigned the obtained values to the tested samples.

Iron scale, both in the form of flakes and powder, is characterized by magnetic soft properties of low values even in relation to ferrites. A lower $B_{\max }$ value results from a different manufacturing process; the tested composites are bonded with a polymer matrix and not sintered as in the case of conventional ferrites.

\subsection{Measurement of Thermomechanical Properties}

Dynamic mechanical thermal analysis (DMTA) allows for analysis of the mechanical properties of the tested material at short load times and varying temperature values. During the test, a sample of defined dimensions is subjected to a sinusoidal varying force. The analysis is carried out in the full temperature range for a given material (below the glass transition temperature up to the pour point). The results of the analysis include the curves of dependence $E^{\prime}$ (conservative modulus), $E^{\prime \prime}$ (loss modulus), and $\tan \delta$ (tangent of the mechanical loss angle) on the temperature or time. The conservative modulus and the loss modulus are components of the complex Young's modulus, expressed by the following equation:

$$
E^{x}=E^{\prime}+i \times E^{\prime \prime},
$$

The conservative modulus is the real part of the equation. It is related to the preservation and release of energy during deformations. For perfectly viscous bodies, its value is equal to zero. In turn, the loss modulus is a measure of the energy dissipated by the 
sample (e.g., as heat). For a perfectly elastic body, both the value of the loss modulus and the tangent of the loss angle are zero. The loss angle tangent can be written by the following equation:

$$
\tan \delta=\frac{E^{\prime \prime}}{E^{\prime}}
$$

For viscoelastic materials, the value of the phase shift angle $(\delta)$ ranges from $0^{\circ}$ to $90^{\circ}$. This is due to the fact that the strain is shifted by the value of the angle $\delta$ in relation to the stress [25-27].

Using the DMTA test, it is possible to determine (among others) resistance to dynamic loads of the material and its ability to irreversibly dissipate and preserve mechanical energy during dynamic loading at various temperatures.

The tests were carried out using the NETZSCH DMA 242 device (Germany). The sample was subjected to three-point sinusoidal bending with a variable force, at frequencies of $1 \mathrm{~Hz}$ and $10 \mathrm{~Hz}$. The samples were heated at a rate of $3{ }^{\circ} \mathrm{C} / \mathrm{min}$ in the temperature range of $-140{ }^{\circ} \mathrm{C}$ to $100{ }^{\circ} \mathrm{C}$. The samples were made of unfilled high-density polyethylene and a mixture of HDPE and flake and dust scale. The collected results are presented in Figures 12 and 13.
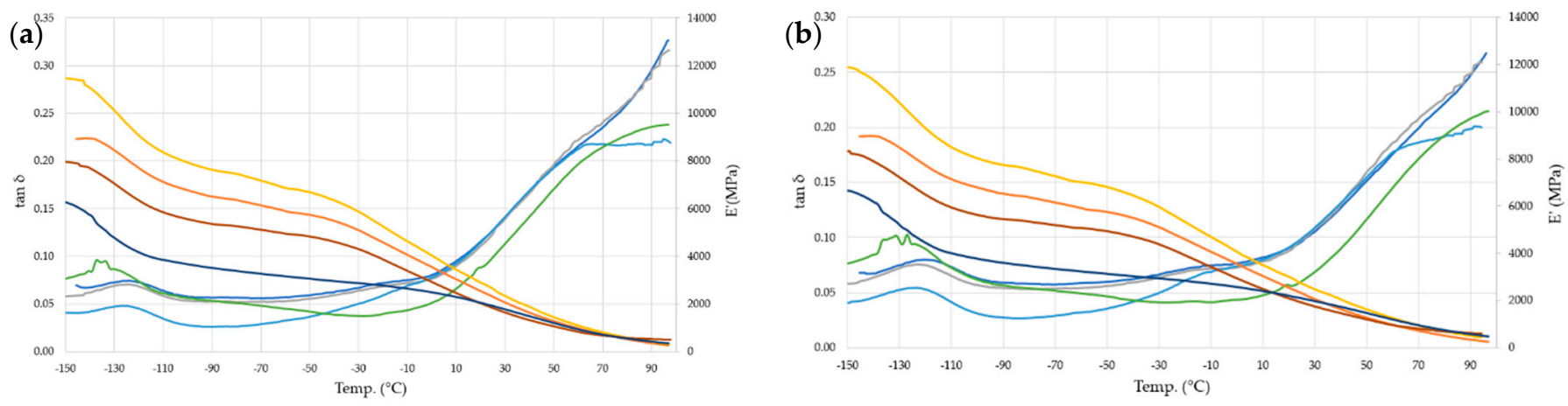

- $\operatorname{tand} 70 / 30-\operatorname{tand} 80 / 20-\operatorname{tand} 90 / 10 \quad$ tand $P E \quad-E^{\prime} 70 / 30-E^{\prime} 80 / 20-E^{\prime} 90 / 10 \quad-E^{\prime} P E$

Figure 12. DMTA charts for flakes samples: (a) vibration frequency $1 \mathrm{~Hz},(\mathbf{b}) 10 \mathrm{~Hz}$.
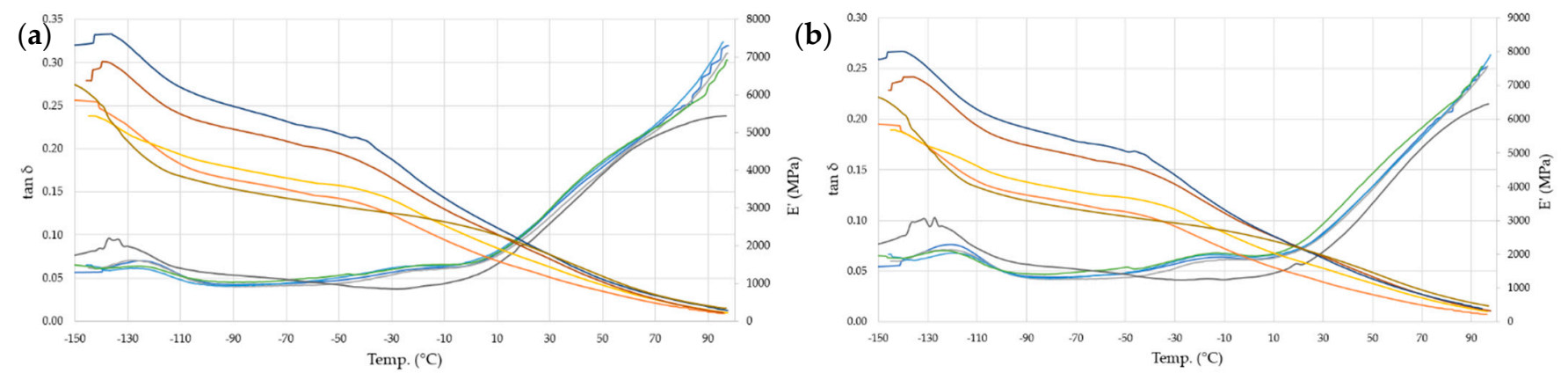

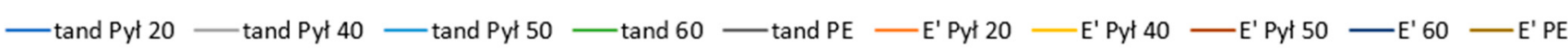

Figure 13. DMTA charts for dust scale samples: (a) vibration frequency $1 \mathrm{~Hz}$, (b) $10 \mathrm{~Hz}$.

The results of the composite measurements shown in Figures 14 and 15 were compared with the pure PE material made by injection molding. This method is much more widely used due to the efficiency of the process. However, it is not useful for composites with high filler content. For the analyzed samples, for both excitation frequencies of $1 \mathrm{~Hz}$ and $10 \mathrm{~Hz}$, the glass transition temperature for the unfilled polyethylene reached a similar value equal to $-127^{\circ} \mathrm{C}$. For the composite samples, in each case, an increase in the glass transition temperature was noted. The highest value, equal to $-114.2{ }^{\circ} \mathrm{C}$, was recorded for the sample 
with $50 \%$ of scale in the form of flakes, with the force operating at a frequency of $10 \mathrm{~Hz}$. The greatest differences in the conservative modulus between the polyethylene and the filled samples were recorded in each case in the glassy phase. For the material without the filler, the value was approximately equal to $6.3 \mathrm{GPa}$ for the excitation frequency of $1 \mathrm{~Hz}$ and approximately $6.7 \mathrm{GPa}$ at the frequency of $10 \mathrm{~Hz}$. In most cases, as a result of the filler addition, an increase in the value of the conservative modulus was recorded. The highest increase, equal to approximately 6.1 GPa, was recorded for samples containing $80 \%$ of scale in the form of flakes. A reduction in the value of the conservative modulus in the vitreous phase was observed for samples with the addition of $20 \%$ and $40 \%$ powder filler and $20 \%$ scale in the form of flakes. For a frequency of $10 \mathrm{~Hz}$, in the case of a sample containing $40 \%$ dust, a decrease in the value of the conservative modulus by about $15 \%$ in relation to polyethylene was recorded. In the case of highly elastic deformations, the courses of the curves of the conservative modulus and the tangent of the loss angle were similar. However, there were still differences in the values. In the highly elastic range, most composites also had a greater influence of temperature on the value of the conservative modulus. At $0{ }^{\circ} \mathrm{C}$, for the unfilled polyethylene, the conservative modulus value was $\sim 2.4 \mathrm{GPa}$ at the frequency of $1 \mathrm{~Hz}$ and $\sim 2.5 \mathrm{GPa}$ at the frequency of $10 \mathrm{~Hz}$. The greatest increase in the conservative modulus was recorded similarly to the glassy phase for composites with the addition of $80 \%$ flake scale. For the frequency of $1 \mathrm{~Hz}$, an increase of $1.9 \mathrm{GPa}$ was registered, whereas for the frequency of $10 \mathrm{~Hz}$, an increase of $2.1 \mathrm{GPa}$ was obtained. The reduction in the conservative modulus at $0{ }^{\circ} \mathrm{C}$ was also noted for composites with $20 \%$ and $40 \%$ dust scale. For samples with $20 \mathrm{wt}$ \% of filler content at a force operating at a frequency of $10 \mathrm{~Hz}$, the reduction in the modulus was $27 \%$. In addition, a reduction in the conservative modulus was noted for the polyethylene with the addition of $20 \mathrm{wt}$ \% of the flake scale. For this composite, a slight increase in the $\mathrm{E}^{\prime}$ value was recorded in the vitreous phase as compared to the unfilled material. In each analyzed case, at a temperature of about $90{ }^{\circ} \mathrm{C}$, that is, in the end-of-use temperature range for polyethylene, the differences in the courses of the conservative modulus curves are small. The modulus had values closer to zero, while the values of the tangent of the loss angle reached their maximum. This indicates that there was a smaller reaction to the extortion of the material and its transition to a viscoid state.

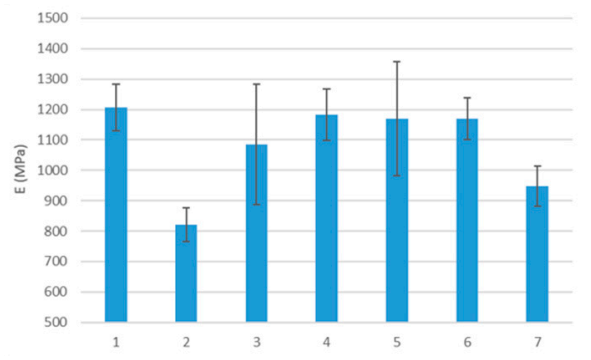

Figure 14. Young's modulus. Samples: (1) HDPE, (2) HDPE with 20\% filler content, (3) HDPE with $40 \%$ filler content, (4) HDPE with 50\% filler content, (5) HDPE with 60\% filler content, (6) HDPE with filler content $70 \%$, (7) HDPE with a filler content of $80 \%$.

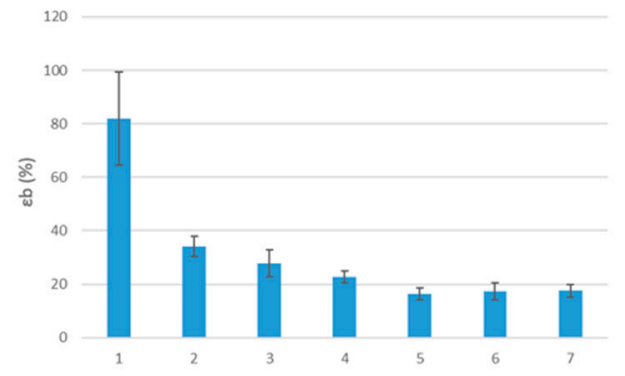

Figure 15. Relative elongation. Samples: (1) HDPE, (2) HDPE with 20\% filler content, (3) HDPE with $40 \%$ filler content, (4) HDPE with 50\% filler content, (5) HDPE with 60\% filler content, (6) HDPE with filler content 70\%, (7) HDPE with a filler content of $80 \%$. 


\subsection{Tensile Strength}

Polymers have a number of physical properties that determine their quality and operational suitability. One of the basic parameters that determines the suitability of a given polymer material is its static tensile strength during the uniaxial deformation of a specimen with specific dimensions at a constant speed and recording the stress $\sigma$ as a function of the deformation $\varepsilon$.

$$
\sigma=f(\varepsilon),
$$

where $\varepsilon$ is the strain, an independent variable, and $\sigma$ is the stress depending on the applied strain.

From this test, it is possible to calculate the basic physical properties of any material-the tensile strength and the ultimate elongation at the break stress and at a specific elongation $[28,29]$. During the test, an increase in the tensile force $F$ is used, which causes an increase in the length from the initial state $l_{0}$ to the value of $l_{\mathrm{x}}$. The absolute elongation is equal to the following:

$$
\Delta l_{x}=l_{x}-l_{0},
$$

where $l_{0}$ is the initial sample length (in millimeters), and $l_{x}$ is the length of the specimen after stretching (in millimeters).

The ratio of the absolute elongation to the initial specimen length expresses the relative elongation $\varepsilon_{\mathrm{b}}$.

$$
\varepsilon_{b}=\frac{l_{x}-l_{0}}{l_{0}}=\frac{\Delta l_{x}}{l_{0}} \cdot 100 \%,
$$

where tensile stress $\sigma$ is the ratio of the tensile force to the cross-sectional area of the specimen.

$$
\sigma=\frac{F}{A_{0}}[M P a],
$$

where $F$ is the deformation force, $(\mathrm{N})$, and $A_{\mathrm{o}}$ is the area of the initial cross-section (in square millimeters).

Using the static tensile test, we determined, among others, the tensile strength of the given material and its maximum elongation, as well as its Young's modulus.

The tests were carried out using the Galdabini Quasar 25 device (Germany) equipped with an extensometer. A sample normalized for the static tensile test with dimensions of $150 \times 10 \times 4$ was subjected to static stretching at a speed of $\mathrm{v}=50 \mathrm{~mm} / \mathrm{min}$. The samples were pressed from HDPE filled with flake scales and compared to pure HDPE injection moldings.

Figures 14-16 show the results of the static tensile tests, including Young's modulus $E$, relative elongation $\varepsilon_{\mathrm{b}}$, and maximum stress $\sigma_{\mathrm{m}}$. Young's modulus $E$ for the standard samples made by an injection molding with HDPE was about $1200 \mathrm{MPa}$. In comparing the base samples to the composite samples made by pressing technology, a decrease in Young's modulus was found. A significant decrease in Young's modulus was noticed in the samples with a $20 \mathrm{wt} . \%$ iron scale content- $0.82 \mathrm{GPa}$. The samples with $40 \mathrm{wt} . \%$ scale filling compared to the composite with $20 \mathrm{wt} . \%$ scale filling had an increase in Young's modulus of about $260 \mathrm{MPa}$, and compared to the reference injection moldings, had a slight decrease of about $115 \mathrm{MPa}$. The addition of iron scale to the HDPE with a content of 50 to $70 \%$ increased Young's modulus compared to the composites with a lower percentage of filler compared to the injection moldings; the difference in Young's modulus was about $30 \mathrm{MPa}$. During the analysis of samples filled with $80 \%$ scale, a decrease in Young's modulus in relation to the basic samples was found to be about $250 \mathrm{MPa}$. The relative elongation $\varepsilon_{\mathrm{b}}$ for the reference samples made by the injection method was about $80 \%$ compared to the composite containing $20 \%$ scale filling; the relative elongation decreased by about $46 \%$. With the increase in the filler, the relative elongation $\varepsilon_{b}$ decreased for the material with a content of $40 \%$ scale; it was about $27 \%$ and lower than the reference sample by $53 \%$. For samples with $50 \%$ content, the decrease compared to the injection HDPE samples was about 
$58 \%$. For samples with $60 \%$ content, the relative elongation $\varepsilon_{\mathrm{b}}$ was about $16 \%$. For samples with $70 \%$ and $80 \%$ scale filling, the relative elongation $\varepsilon$ b was about $17 \%$. The maximum stresses $\sigma \mathrm{m}$ for the reference samples made by the injection method was about $28 \mathrm{MPa}$ compared to the composite with $20 \%$ filler content; a decrease in the maximum stress $\sigma \mathrm{m}$ by about $13 \mathrm{MPa}$ was noticed. As the filler content increased, the maximum stresses om for composites with 40 to $60 \%$ scale was about $11 \mathrm{MPa}$, and it was lower than the reference samples by $18 \mathrm{MPa}$. For samples with $70 \%$ scale content, the maximum stresses om were about $8 \mathrm{MPa}$ and $7 \mathrm{MPa}$ for the composites filled with $80 \%$ iron scale.

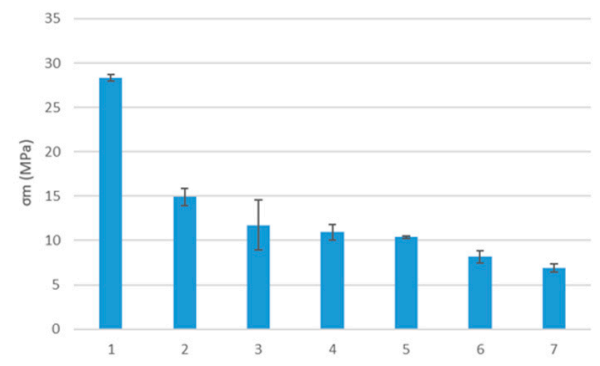

Figure 16. Stress maximums. Samples: (1) HDPE, (2) HDPE with 20\% filler content, (3) HDPE with $40 \%$ filler content, (4) HDPE with 50\% filler content, (5) HDPE with 60\% filler content, (6) HDPE with filler content $70 \%$, (7) HDPE with a filler content of $80 \%$.

\subsection{Shielding Properties}

The produced composite samples were used to verify the effectiveness of the shielding. The measurements were performed on a stand equipped with a generator operating in the $\mathrm{X}$ and $\mathrm{K}$ bands (Figure 17). For this purpose, an open waveguide (R100) at one end was used, powered from an HP 70004A 1-20 GHz generator (from Agilent Technologies, USA) in the 8.2 to $12.4 \mathrm{GHz}$ range (waveguide $\mathrm{R} 220$ for $23 \mathrm{GHz}$ ). A horn antenna was mounted at the end of the waveguide, and at a distance of $1 \mathrm{~cm}$, there was a second horn antenna of the receiver with an MDL 90DH389-1R (Microwave Development Laboratories, USA) microwave detector. The detector output voltage was measured with a digital multimeter. The tested composite plate was placed in the gap between the open end of the waveguide and the antenna (Figure 18). First, the voltage level was measured without the board, and then with the board. The ratio of these tensions determined the effectiveness of the shielding. Measurements were made at ten locations on the sample and the average of these measurements was taken as the result.

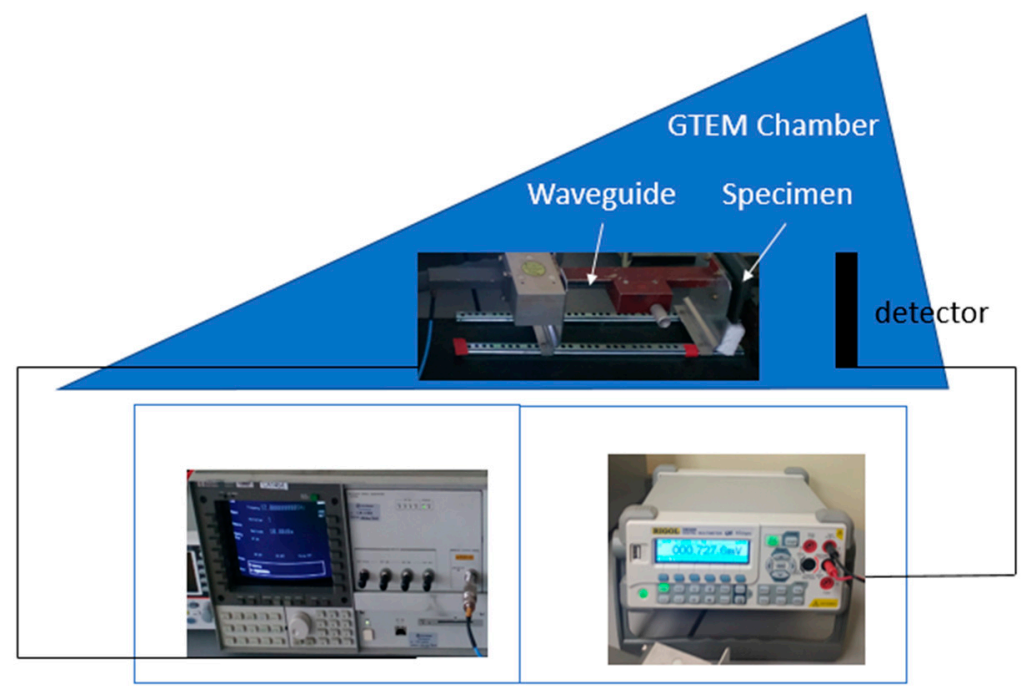

Figure 17. View of the shielding effectiveness measuring stand. 


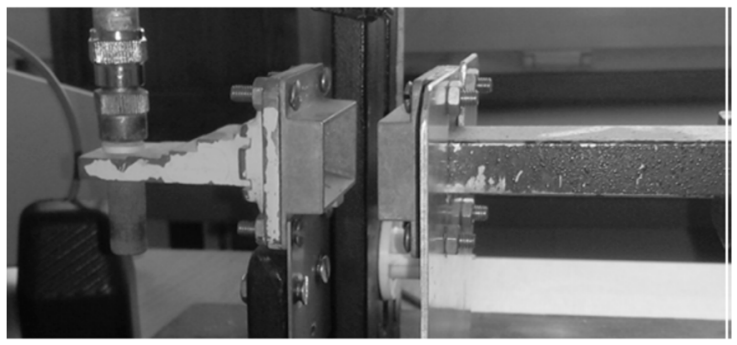

Figure 18. Waveguide and the horn antenna.

The level of EMI shielding was measured in six composites of flake scale with HDPE powder (20-80\%), four composites with dust (20-60\%), and three composites of the mixed type $(50 \%$ scale, including mix $70-70 \%$ flakes; $30 \%$ powder, mix $80-80 \%$ flakes; $20 \%$ powder, mix 90 - $90 \%$ flakes; $10 \%$ powder).

The higher the SE value in decibels, the lower the energy passing through the sample. All measured SE values can be considered a combination of electromagnetic radiation, that is, reflection from the material surface, energy absorption, and multiple internal radiation reflections. As shown in Figures 19-21, the SE increased with the increasing fraction of the ferromagnetic filler. It is an almost linear relationship that correlates positively with the material density (0.93-0.97) and negatively with the sample resistance $(-0.53--0.67)$.

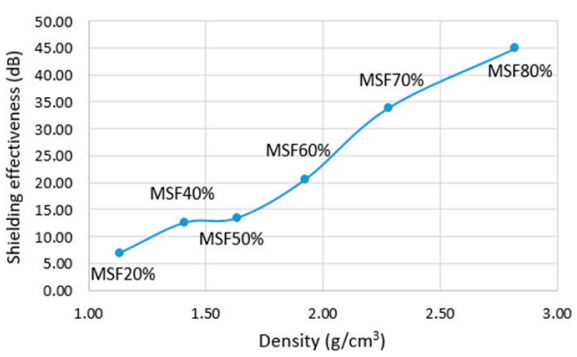

Figure 19. SE dependence of density. Iron scale flakes. Frequency-10 GHz.

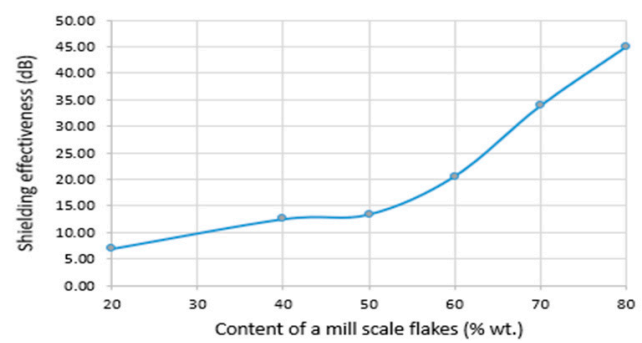

Figure 20. SE dependence of content of iron scale flakes. Frequency-10 GHz.

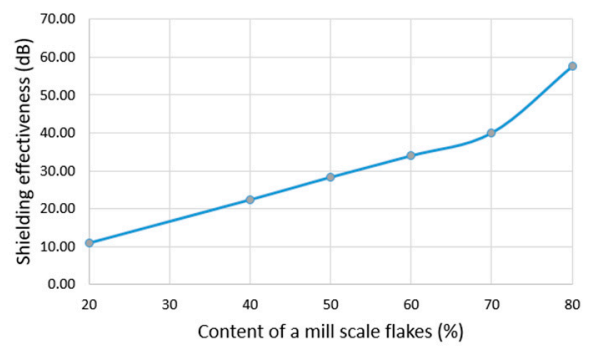

Figure 21. SE dependence of content of iron scale flakes. Frequency-23 GHz.

Iron scale in the form of flakes finds recipients and is used, for example, for the production of concrete mixtures as weights for washing machines and ship ballast. Very 
fine dust is a much more difficult material to use. Therefore, the composites made of sludge, which, after drying, turns into a powder, were also verified. The results of measuring the shielding effectiveness of samples made from iron dust scale are shown in Figures 22-24.

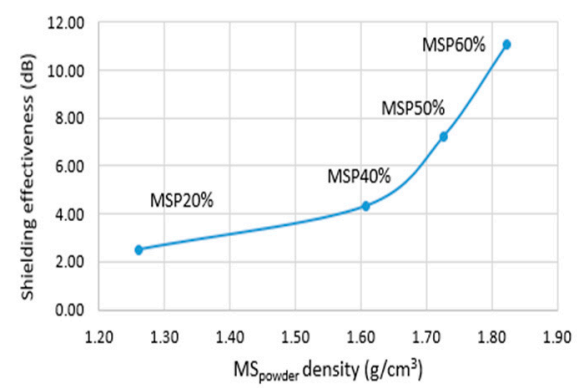

Figure 22. SE dependence of density. Iron scale powder. Frequency-10 GHz.

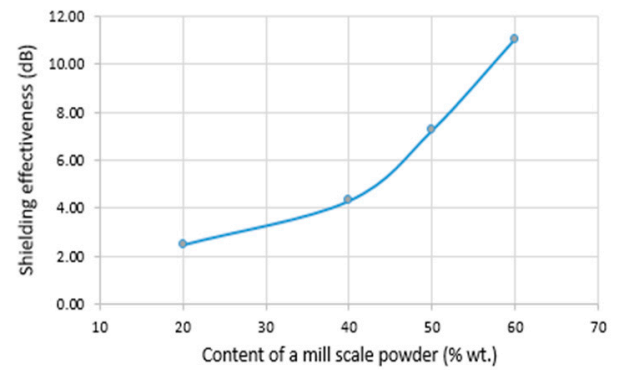

Figure 23. SE dependence of content of iron scale powder. Frequency-10 GHz.

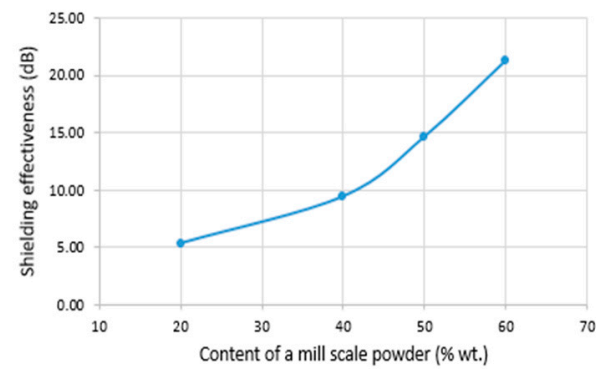

Figure 24. SE dependence of content of iron scale flakes. Frequency-23 GHz.

Additionally, in the case when the dust scale was applied, the shielding effectiveness depended on the fraction of the filler. Then, the relationship was exponential with a positive correlation for density $(0.95-0.96)$ and a negative one for the electrical resistance $(-0.7-0.75)$.

For the third version of the samples, the flakes were mixed with the scale powder at three different fractions $\left(\mathrm{F}_{70} \mathrm{D}_{30}, \mathrm{P}_{80} \mathrm{D}_{20}\right.$, and $\left.\mathrm{F}_{90} \mathrm{D}_{20}\right)$ at a constant weight fraction of the HDPE powder (50 wt.\%). The results are shown in Figures 25-27.

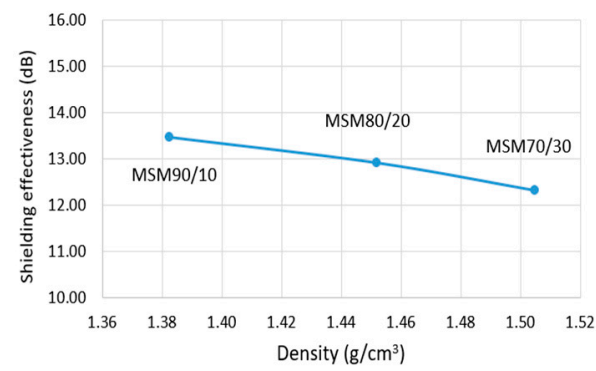

Figure 25. SE dependence of density. Iron scale mix of flakes and powder. Frequency-10 GHz. 


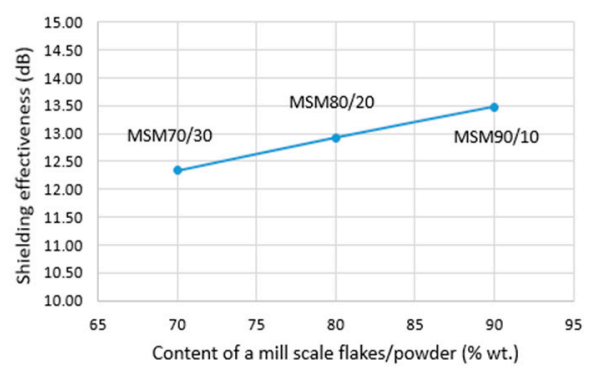

Figure 26. SE dependence of content of iron scale mix of flakes and powder. Frequency-10 GHz.

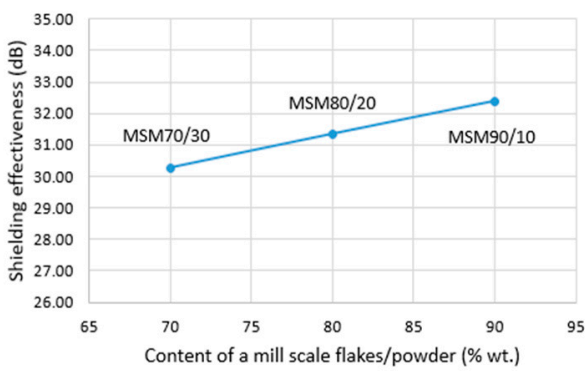

Figure 27. SE dependence of content of iron scale mix of flakes and powder. Frequency-23 GHz.

The obtained results were comparable to the SE values obtained for the scale in the form of flakes. However, according to the results of the measurements of mechanical parameters, a higher proportion of dust was conducive to a greater brittleness of the samples.

The detailed characteristics of the shielding effectiveness for samples made of iron flake scale (IFS) filler from 20 to $70 \%$ are shown in Figure 28.

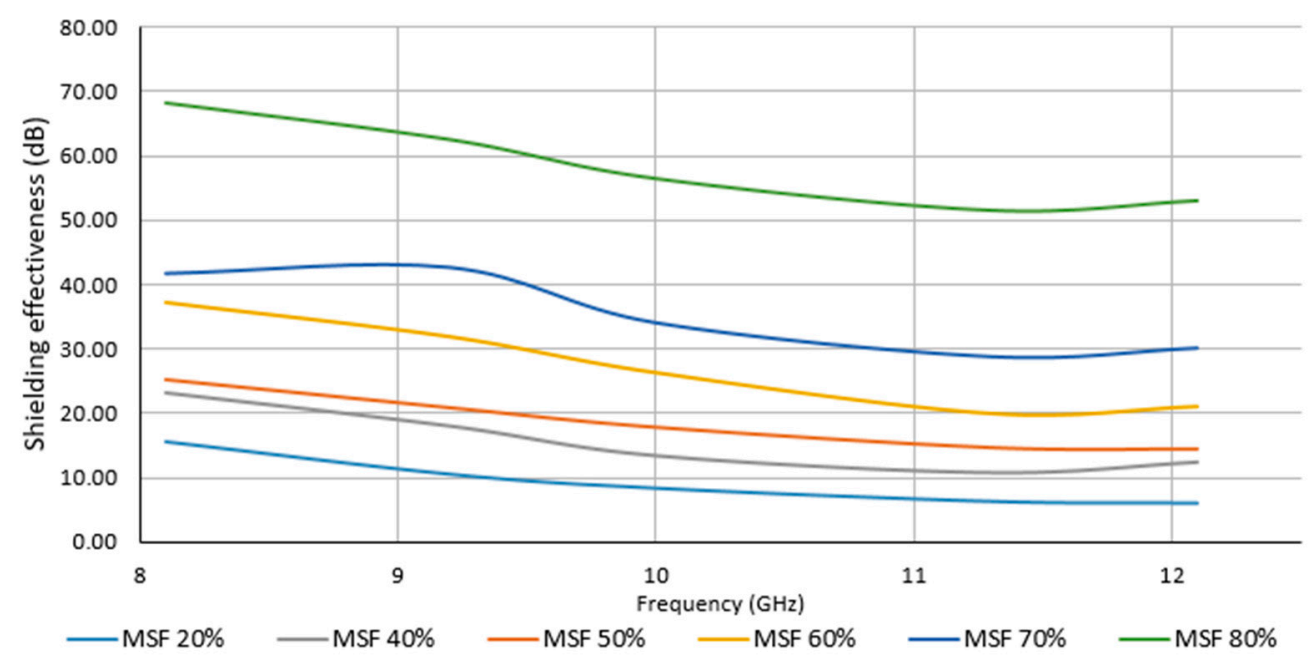

Figure 28. SE dependence on the weight fraction of the filler (iron flake scale).

The values we obtained were compared to the results obtained by other researchers. The use of $70 \%$ filling with a cover thickness of $2 \mathrm{~mm}$ ensures that the radiation is attenuated by over $50 \mathrm{~dB}$. This level is often better than other composite materials based on nonmetallic fillers, and comparable to sandwich composites containing, for example, aluminum (Table 2). A good example is a textile composite with a vacuum-applied aluminum layer, which achieved a shielding efficiency of $42 \mathrm{~dB}$ [30]. Another example is a sandwich composite made of natural fiber mats and an ultra-thin aluminum sheet bonded with epoxy resin [31]. The SE values of this composite, depending on the number of aluminum sheet layers, reached $30-53 \mathrm{~dB}$. 
Table 2. EMI shielding properties of different composite materials reported in the literature.

\begin{tabular}{|c|c|c|c|}
\hline Materials (Thickness) & Frequency Range & SE (dB) & Ref. \\
\hline Carbon fiber- $-\mathrm{Fe}_{3} \mathrm{O}_{4} 0(1.0 \mathrm{~mm})+$ epoxy & 8.2-12.4 GHz & 51.5 & {$[32]$} \\
\hline Carbon fiber- $-\mathrm{Fe}_{3} \mathrm{O}_{4} 0(3.5 \mathrm{~mm})+\mathrm{EVA}$ & 8.2-12.4 GHz & 34.1 & [33] \\
\hline $\begin{array}{c}\text { Composites with } \mathrm{Fe}_{3} \mathrm{O}_{4} \text { nano particles of } \\
1.0 \mathrm{wt} . \% \text { and carbon fibers }\end{array}$ & $8-12 \mathrm{GHz}$ & $\geq 20$ & {$[34]$} \\
\hline Ceramic brick with (up to) $20 \%$ of mill scale & $8-12 \mathrm{GHz}$ & $\leq 8$ & [9] \\
\hline Fiberglass $\mathrm{Al}$ cover $(0.2 \mathrm{~mm} / \mathrm{Al} 210 \mathrm{~nm})$ & 8.1-12.1 GHz & $>40$ & {$[30]$} \\
\hline $\begin{array}{l}\text { Natural fiber and aluminum sheet } \\
\text { hybrid composites }\end{array}$ & $8-12 \mathrm{GHz}$ & $<54$ & [31] \\
\hline $\mathrm{NCS} / \mathrm{Fe}(1.2 \mathrm{~mm})$ & $8-12 \mathrm{GHz}$ & $<30$ & [35] \\
\hline PVDF/Fe3O4-8\%CNT (1.1 mm) & $18-26.5 \mathrm{GHz}$ & $<23$ & [36] \\
\hline $\begin{array}{l}\text { Shielding fabric ( } 80 \% \text { nylon, } 20 \% \text { silver, } \\
\text { specific weight: } 45 \mathrm{~g} / \mathrm{m}^{2} \text {.) }\end{array}$ & $8-12 \mathrm{GHz}$ & $<60$ & [37] \\
\hline $\begin{array}{l}\text { MCL61/EMI foil (Composition: polyester, } \\
\text { Co, Fe, Mo, Nb, Si, B. Material thickness: } \\
0.1 \mathrm{~mm})\end{array}$ & $8-12 \mathrm{GHz}$ & $<90$ & [38] \\
\hline HDPE-IS $_{\text {Flakes }} 70 \%(2 \mathrm{~mm})$ & $8.1-12.1 \mathrm{GHz}$ & $<52$ & Present work \\
\hline HDPE-IS Flakes $50 \%$ (2 mm) & $8.1-12.1 \mathrm{GHz}$ & 25.3 & Present work \\
\hline HDPE-IS ${ }_{\text {Powder }} 60 \%$ (2 mm) & $8.1-12.1 \mathrm{GHz}$ & 11 & Present work \\
\hline HDPE-IS $_{M i x} 50 \% 90 / 10(2 \mathrm{~mm})$ & 8.1-12.1 GHz & 13.5 & Present work \\
\hline
\end{tabular}

Other examples of materials used for shielding EM fields that are already commercially available are fabrics and foils [37,38]. SILVER-SILK is a silver-plated parachute silk/nylon fabric for shielding high-frequency electromagnetic radiation (HF) and low-frequency alternating electric fields (LF). It is typically used in preferably technical applications for shielding cables, mobile phone cases, as room dividers, and so forth. The manufacturer quotes a material price of EUR 54.88/square meter. On the other hand, MCL61 is a magnetic field shielding film made from an amorphous cobalt alloy. The foil is not MUMETALL®. Compared to MUMETALL $\AA$, MCL61 has many advantages-MUMETALL®is soft and sensitive, and the shielding is quickly lost during bending, impact, and processing. The cobalt strips are flexible even at small bending radii but still hard. The shielding attenuation is maintained even under high mechanical stress. The manufacturer quotes a material price of EUR 137/square meter. Compared to the presented materials, iron scale for the production of the described screens can be sourced in the European Union at a price below EUR $65 / \mathrm{Mg}$, and the cost of HDPE powder is about EUR $2.5 / \mathrm{kg}$. In general, iron scale is waste that causes problems for steel producers. Consequently, its prices are much lower than scrap steel and other metals. Iron scale is also widely available, unlike nanocarbon and other nanoparticles. In the case described, $4 \mathrm{~kg}$ of ingredients are needed to cover one square meter with our tiles ( $2 \mathrm{~mm}$ thick). For a sample of $70 \%$, this is $2.8 \mathrm{~kg}$ of iron scale and $1.2 \mathrm{~kg}$ of HDPE, respectively.

\section{Conclusions}

The results of the investigations performed in the work confirmed the usefulness of iron scale in the construction of electromagnetic field shields from a waste material; it is easy to obtain and cheap. HDPE is also a commonly used polymer that can easily be recycled. The features of these materials mean that in situations where the thickness of the barrier is not crucial, it is possible to obtain satisfactory shielding effects at a low cost.

The filler content is a major factor in the overall SE value for all types of composites. 
- Iron scale in the form of flakes provides the highest level of SE in relation to the filler content.

- Flake scale composites have better mechanical properties than dust-filled composites.

- The developed composites are easy to form and utilize materials easy for recycling.

- Generally, iron scale is a waste that causes trouble for steelmakers. As a result, it is also widely available, unlike nanocarbon and other nanoparticles.

- The cost of making one square meter of shielding from the proposed composite is lower than alternative commercial materials, such as MUMETAL ${ }^{\circledR}$, copper and aluminum plates, or silver-plated fabrics. However, it was not an economic factor but an ecological one that was the dominant need satisfied by the offered solution.

The presented solution is an alternative to screens and plastic enclosures covered with paint or conductive layers, such as aluminum. The use of recycled (and recyclable) materials is much less harmful to the environment than the paints and sprays used to paint plastic, which contain very harmful solvents. We have shown that the developed composite has sufficient thermo-mechanical properties (Young's modulus and DMTA) for the construction of stable screens and enclosures while imparting anti-electrostatic and electromagnetic field-shielding properties with efficiencies above $50 \mathrm{~dB}$.

Maintaining satisfactory thermo-mechanical parameters while ensuring high electromagnetic field shielding efficiency involved difficulties due to, for example, increased brittleness of the composite with increased filler content, as well as a lack of stability and repeatability in the manufacturing process.

In the next step, the authors will extend the research to doping the composite with other recycling materials, for example, based on amorphs and nanocrystals.

Author Contributions: Conceptualization: A.J. and Ł.S.; methodology: A.J., Ł.S. and M.M.; formal analysis, E.Ł.-T.; investigation, A.J., E.Ł.-T., M.M. and Ł.S.; resources, A.J. and Ł.S.; writing—original draft preparation, A.J., M.M. and Ł.S.; writing—review and editing, E.Ł.-T.; visualization, E.Ł.-T.; supervision, A.J.; project administration, A.J.; funding acquisition, A.J. All authors have read and agreed to the published version of the manuscript.

Funding: This research was funded by The National Centre for Research and Development of Poland, grant number LIDER/11/0049/L10/18/NCBR/2019, grant title: Eco-innovative composite materials using recycled raw materials for electrical engineering applications. The APC was funded by grant number LIDER/11/0049/L10/18/NCBR/2019.

Acknowledgments: In this section, you can acknowledge any support given which is not covered by the author contribution or funding sections. This may include administrative and technical support, or donations in kind (e.g., materials used for experiments).

Conflicts of Interest: The authors declare no conflict of interest.

\section{References}

1. Tansel, B. From electronic consumer products to e-wastes: Global outlook, waste quantities, recycling challenges. Environ. Int. 2017, 98, 35-45. [CrossRef] [PubMed]

2. Gubanova, E.; Kupinets, L.; Deforzh, H.; Koval, V.; Gaska, K. Recycling of polymer waste in the context of developing circular economy. Archit. Civ. Eng. Environ. 2019, 12, 99-108. [CrossRef]

3. Söderholm, P.; Ekvall, T. Metal markets and recycling policies: Impacts and challenges. Miner. Econ. 2020, 33, 257-272. [CrossRef]

4. Non-Binding Guide to Good Practice for Implementing Directive 2013/35/EU Electromagnetic Fields. Available online: https: / / op.europa.eu/en/publication-detail/- / publication/c6440d35-8775-11e5-b8b7-01aa75ed71a1 (accessed on 21 December 2021).

5. Geetha, S.; Satheesh Kumar, K.K.; Rao, C.R.; Vijayan, M.; Trivedi, D.C. EMI shielding: Methods and materials-A review. J. Appl. Polym. Sci. 2009, 112, 2073-2086. [CrossRef]

6. Fang, K.; Wang, T.; Yuan, X.; Miao, C.; Pan, Y.; Li, J. Detection of weak electromagnetic interference attacks based on fingerprint in IIoT systems. Future Gener. Comput. Syst. 2022, 126, 295-304. [CrossRef]

7. Communication from The Commission to The European Parliament, The Council, The European Economic and Social Committee and The Committee of The Regions. Connectivity for a Competitive Digital Single Market-Towards a European Gigabit Society; European Committee for Standardization: Brussels, Belgium, 2016; COM(2016) 587 final.

8. List of Common EMC Test Standards. Available online: https://en.wikipedia.org/wiki/List_of_common_EMC_test_standards (accessed on 12 October 2021). 
9. Bantsis, G.; Sikalidis, C.; Betsiou, M.; Yioultsis, T.; Xenos, T. Electromagnetic absorption, reflection and interference shielding in $\mathrm{X}$-band frequency range of low cost ceramic building bricks and sandwich type ceramic tiles using mill scale waste as an admixture. Ceram. Int. 2011, 37, 3535-3545. [CrossRef]

10. Hayes, P.R. Efficient EMI characterization of unshielded buildings. 2005 IEEE Antennas Propag. Soc. Int. Symp. 2015, 3, 256-259.

11. Chung, D.D.L. Electromagnetic interference shielding effectiveness of carbon materials. Carbon 2001, 39, 279-285. [CrossRef]

12. Li, L.; Chung, D.D.L. Electrical and mechanical properties of electrically conductive polyethersulfone composites. Composites 1994, 25, 215-224. [CrossRef]

13. Pradhan, S.S.; Unnikrishnan, L.; Mohanty, S.; Nayak, S.K. Thermally conducting polymer composites with EMI shielding: A review. J. Electron. Mater. 2020, 49, 1749-1764. [CrossRef]

14. Yoshida, S.; Sato, M.; Sugawara, E.; Shimada, Y. Permeability and electromagnetic-interference characteristics of Fe-Si-Al alloy flakes-polymer composite. Int. J. Appl. Phys. 1999, 85, 4636-4638. [CrossRef]

15. Xu, C.; Liu, J.; Zhu, X.; Zhu, Y.; Xiong, X.; Cheng, X. Electromagnetic interference shielding boards produced using Tetra Paks waste and iron fiber. J. Mater. Cycles Waste Manag. 2015, 17, 391-398. [CrossRef]

16. Willard, M.A.; Laughlin, D.E.; McHenry, M.E.; Thoma, D.; Sickafus, K.; Cross, J.O.; Harris, V.G. Structure and magnetic properties of (Fe 0.5 Co 0.5) 88 Zr 7 B 4 Cu 1 nanocrystalline alloys. Int. J. Appl. Phys. 1998, 84, 6773-6777. [CrossRef]

17. Institute of Electrical and Electronics Engineers (IEEE). IEEE standard method for measuring the effectiveness of electromagnetic shielding enclosures. IEEE Std 299.1-2013 2014, 1-96. [CrossRef]

18. Benhamou, S.M.; Hamouni, M. Determination of reflection loss, absorption loss, internal reflection and shielding effectiveness of a double electromagnetic shield of conductive polymer. J. Mater. Environ. Sci. 2014, 5, 1982-1987.

19. Xiao, L. Shielding Effectiveness (SE) Measurement for Maxair Waveguide Panel, Lossy Material Evaluation by Laptop Application. Master's Thesis, Missouri University of Science and Technology, Rolla, MO, USA, 2014; p. 7316.

20. Jakubas, A.; Łada-Tondyra, E.; Makówka, M.; Chyra, M.; Sochacka, O.; Suchecki, Ł. Concept of Using Recycled Raw Materials for the Production of Composite Soft Magnetic for shielding of electromagnetic field. Prz. Elektrotechniczny 2020, 97, 182-185. [CrossRef]

21. Bambynek, D.; Jabłoński, P.; Jakubas, A. Attenuation of High Frequency Electromagnetic Waves by Polymer Composites with Waste Materials. In 2018 Applications of Electromagnetics in Modern Techniques and Medicine (PTZE); IEEE Xplore: Piscataway, NJ, USA, 2018; pp. 1-4.

22. Garnaud, G.; Rapp, R.A. Thickness of the oxide layers formed during the oxidation of iron. Oxid. Met. 1977, 11, 193-198. [CrossRef]

23. Mohamed, A.T.; Mobarak, Y. Thermal Experimental Analysis for Dielectric Characterization of High Density Polyethylene Nanocomposites. Adv. Electr. Electron. Eng. 2016, 14, 295-303. [CrossRef]

24. Azis, R.A.S.; Hashim, M.; Saiden, N.M.; Daud, N.; Shahrani, N.M.M. Study the iron environments of the steel waste product and its possible potential applications in ferrites. Adv. Mat. Res. 2015, 1109, 295-299. [CrossRef]

25. Wetton, R.E.; Marsh, R.D.L.; Van-de-Velde, J.G. Theory and application of dynamic mechanical thermal analysis. Thermochim. Acta 1991, 175, 1-11. [CrossRef]

26. Kijo-Kleczkowska, A.; Gnatowski, A.; Szumera, M.; Otwinowski, H.; Kwiatkowski, D.; Suchecki, Ł. Effect of addition of coal sludge to polymeric material on thermal effects in analysis by TG/DTG/DSC methods. In E3S Web of Conferences. EDP Sci. 2020, 154, 03002. [CrossRef]

27. Jakubas, A.; Chyra, M.; Gnatowski, A. The Influence of Reinforcement Fibers on Mechanical and Electrical Properties of the Electrical Engineering Composites. Acta Phys. Pol. A 2019, 135, 193-195. [CrossRef]

28. Broniewski, T.; Kapko, J.; Płaczek, W.; Thomalla, J. Metody Badań i Ocena Właściwości Tworzyw Sztucznych; WNT: Warszawa, Poland, 2000; pp. 39-43.

29. EN ISO 527-2:2012. Plastics_Determination of Tensile Properties—Part 2: Test Conditions for Moulding and Extrusion Plastics; European Committee for Standardization: Brussels, Belgium, 2012.

30. Łada-Tondyra, E.; Jakubas, A.; Figiel, M. The research and the analysis of electromagnetic field shielding properties of the textile materials with an electroconductive coating. Przeglad Elektrotechnczny 2021, 97, 133-136. [CrossRef]

31. Xia, C.; Yu, J.; Shi, S.Q.; Qiu, Y.; Cai, L.; Wu, H.F.; Zhang, H. Natural fiber and aluminum sheet hybrid composites for high electromagnetic interference shielding performance. Compos. Part B Eng. 2017, 114, 121-127. [CrossRef]

32. Chen, W.; Wang, J.; Zhang, B.; Wu, Q.; Su, X. Enhanced electromagnetic interference shielding properties of carbon fiber veil/ $\mathrm{Fe}_{3} \mathrm{O}_{4}$ nanoparticles/epoxy multiscale composites. Mater. Res. Express 2017, 4, 126303. [CrossRef]

33. Das, N.C.; Khastgir, D.; Chaki, T.K.; Chakraborty, A. Electromagnetic interference shielding effectiveness of carbon black and carbon fibre filled EVA and NR based composites. Compos. Part A Appl. Sci. Manuf. 2000, 31, 1069-1081. [CrossRef]

34. Yesmin, N.; Chalivendra, V. Electromagnetic Shielding Effectiveness of Glass Fiber/Epoxy Laminated Composites with MultiScale Reinforcements. J. Compos. Sci. 2021, 5, 204. [CrossRef]

35. Jia, Z.; Kou, K.; Yin, S.; Feng, A.; Zhang, C.; Liu, X.; Wu, G. Magnetic Fe nanoparticle to decorate N dotted C as an exceptionally absorption-dominate electromagnetic shielding material. Compos. Part B Eng. 2020, 189, 107895. [CrossRef]

36. Cheng, H.; Wei, S.; Ji, Y.; Zhai, J.; Zhang, X.; Chen, J.; Shen, C. Synergetic effect of Fe3O4 nanoparticles and carbon on flexible poly (vinylidence fluoride) based films with higher heat dissipation to improve electromagnetic shielding. Compos. Part A Appl. Sci. Manuf. 2019, 121, 139-148. [CrossRef]

37. YSHIELD®SILVER-SILK Fabric Data Sheet. Available online: https://www.yshield.com/ (accessed on 21 December 2021).

38. YSHIELD®MCL61 EMI Foil Data Sheet. Available online: https:/ / www.yshield.com/ (accessed on 21 December 2021). 